\title{
КАК ИГРА ПОМОГАЕТ УЧИТЬСЯ
}

\section{(C) Эзербаев И.Е.}

ФГБОУ ВО «Грозненский государственный нефтяной технический университет имени академика М.Д. Миллионщикова» г. Грозный

В данной статье рассматривается вопрос применения игровых технологий в образовательной сфере. Выделяются функции игры. Сегодня видеоигры и игровые технологии становятся значимой частью современных образовательных технологий. Форма игры сохраняет свою притягательность, способность удовлетворять потребности в самореализации, соревновании и достижении успеха.

Ключевые слова: образование, игровые технологии, мотивация, вовлечение.
\end{abstract}

Игры делают детей счастливее и намного лучше готовят к жизни, чем привычные уроки. В этом уверен автор книги «Свобода учиться» Питер Грей. Он помогает родителям по-новому взглянуть на процесс обучения и понять, насколько значима игра в жизни ребёнка.

Использование существующих и новых инструментов в области образования становится волнующей темой для педагогов и учебных заведений.

С каждым днем информационным технологиям уделяют все большее внимание в современной системе образования. Каждый год появляется множество новых методов преподавания, которые основываются на современных технологиях. Не все они просты в использовании, но темнее менее, с их помощью образовательный процесс становится все более увлекательным, а изучаемый материал усваивается быстрее. Такие выводы можно сделать, основываясь на результатах неоднократно проводимых исследований среди школьников и студентов. Так как молодое поколение всегда проявляет большой интерес к новым технологиям, существует необходимость преподносить информацию в актуальной для них форме, отвечающей современным запросам. Например, в виде инновационного учебно-методического обеспечения: электронных учебников, симуляций, «серьезных игр» и виртуальных классов. 
С точки зрения восприятия учебного материала наиболее значительным преимуществом игр и симуляторов (или тренажеров), созданных с помощью этой технологии, является способность симулятора перенести учащегося в реалистичную игровую ситуацию. В правильно спроектированном симуляторе учащийся должен действовать так же, как и в аналогичной жизненной ситуации. Это делает полученные знания в большей степени применимыми к жизни, чем знания, полученные в аудитории, вовсе не похожей на места, в которых учащимся в будущем придется применять полученные навыки. Благодаря своим визуальным возможностям, электронный симулятор может быть более реалистичным, чем лекция. А более реалистичный учебный материал лучше усваивается [1].

Как быстро развивающиеся технологические приложения, игры и симуляторы уже широко интегрированы в традиционный образовательный процесс. Они широко используются в сфере образования, при этом уже существует работа, посвященная изучению взаимосвязи между играми и обучением (Yang, Chen, \& Jeng, 2010 ; Chiang, Lin, Cheng, \& Liu, 2011). В последние годы цифровые или сетевые игры все больше поддерживают обучение. В контексте онлайн-образования эта область исследований вызывает значительный интерес со стороны научного и образовательного сообщества, например, преподавателей, студентов и дизайнеров игр. С растущим развитием технологий преподаватели и те, кто разрабатывает образовательную политику, заинтересованы во внедрении инновационных технологических инструментов, таких как видеоигры, виртуальные миры и массовые многопользовательские онлайн-игры (MMPOG) (Buckless, 2014 ; Gómez, 2014 ).

Игры и симуляторы демонстрируют неоднозначные эффекты в ряде секторов, таких как успеваемость учащихся, вовлеченность и мотивация к обучению. Однако, поскольку эти исследования сосредоточены только на определенных дисциплинах, в литературе остается пробел, касающийся четких рамок использования в академических программах. В результате вопрос об эффективной интеграции игр и симуляторов в учебный процесс часто остается на усмотрение преподавателя. Соответственно, цель данной статьи - разработать структуру, которая позволит преподавателям различных дисциплин лучше понять преиму- 
щества и недостатки игр и симуляторов, специфичных для их педагогических целей.

Исследователи решили изучить эффективность игр и симуляций в процессе обучения и сразу же столкнуться с первой проблемой, связанной с отсутствием четких эмпирических данных по этому вопросу (Farrington, 2011). Область науки слишком обширна и требует дальнейшего изучения. Более того, в настоящее время не существует официальных рамок политики или руководящих принципов, рекомендованных правительствами или образовательными учреждениями по внедрению игр и симуляторов в образовании. Так обстоит дело во многих странах Европы, США и Австралии, где инструктор или учреждение обязаны включить игры в учебную программу.

В 2007-2019 годах команда нью-йоркских геймдизайнеров руководила некоммерческую компанию Institute of Play. Исходя из принципов геймдизайна, они разрабатывали проекты школ, продумывали образовательные программы, учебные планы и даже проводили корпоративные семинары.

B Institute of Play предлагали собственную модель обучения - Quest to Learn, которая основывается не только на видеоиграх, но на игровых механиках в целом.

По похожему принципу работают и некоторые образовательные интернет-ресурсы. Codecademy в игровом формате обучает программированию. Duolingo позволяет изучать языки и получать виртуальные награды.

Даже таких серьезных специалистов, как хирурги, скоро можно будет обучать с помощью видеоигр.

Исследование доктора Сами Килика и его коллег (Техасский университет в Галвестоне), согласно которому шутеры от первого лица способны улучшать соответствующие навыки у хирургов.

В литературе, связанной с цифровыми играми, встречается широкий спектр терминов и определений, в основном из-за существования множества цифровых носителей, предназначенных для игр. Как следствие, значение цифровых игр стало синонимом широкого диапазона терминов, таких как компьютерные игры, цифровые игры, электронные игры и видеоигры. Краткое определение цифровых игр влечет за собой их описание как широкий спектр цифровых приложений, характеризующихся некоторыми общими элементами (например, игровой средой, 
активным участием игрока, элементом интерактивности и более широким использованием мультимедиа).

Цифровые обучающие игры считаются привлекательными из-за их развлекательных функций в сочетании с приятной средой, эстетическим качеством (графика, эффекты, музыка), наличием структурированной структуры, их учебными целями (также представляемыми как проблемы, требующие решения), и наличие игрового измерения (вызывающего также активное участие учащегося). В качестве подхода к обучению цифровые образовательные игры считаются современными инструментами обучения и современной средой обучения, выводя образование на новый уровень. При правильном использовании в организованной среде обучения (с конкретными целями обучения, соответствующим развивающим дизайном и оценкой) цифровые образовательные игры можно классифицировать как среду активного обучения.
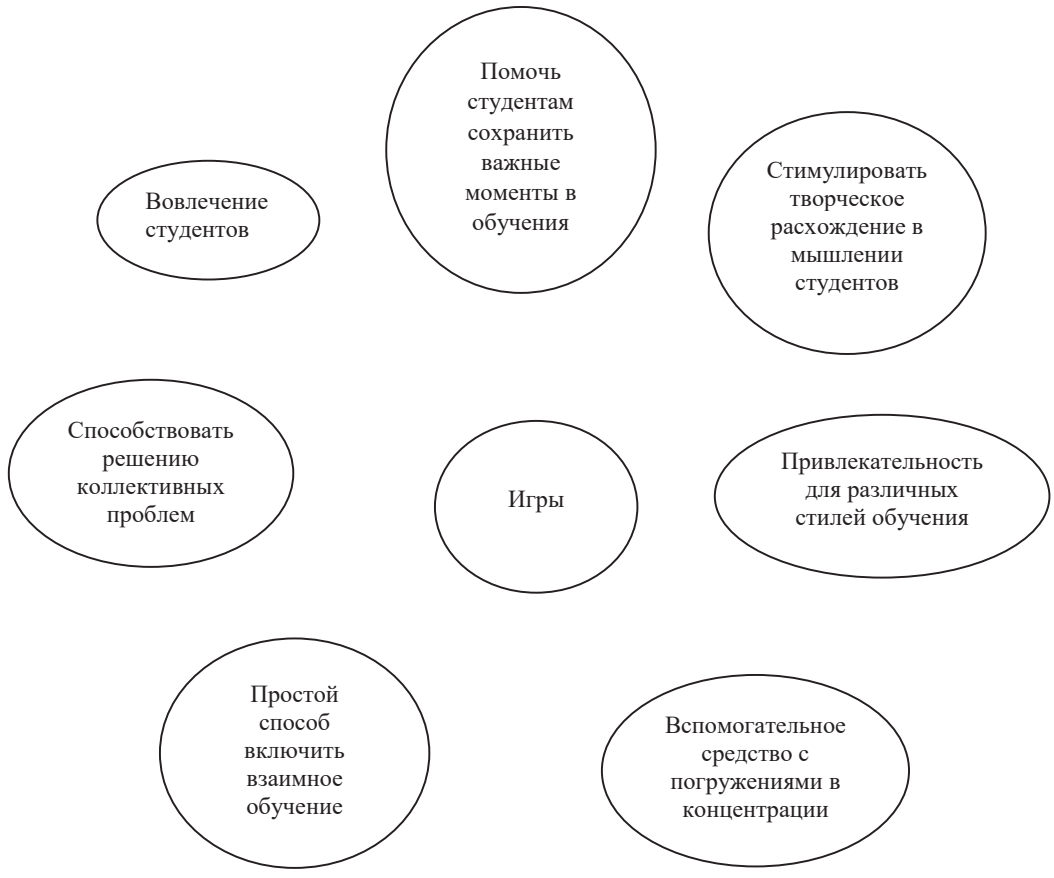

Рис. 1. Роль игры в обучении 
Конкретное применение игр в образовании дает много преимуществ в процессе обучения. Как правило, обучающие видеоигры и тренажеры обучают многим навыкам, таким как алгебра, биология, компьютерное программирование и летная подготовка. В частности, игры-симуляторы могут развить у детей мягкие навыки. Они действительно могут повысить чувство собственного достоинства у детей и улучшить навыки социализации, лидерские качества и командообразование.

Давайте посмотрим, каковы преимущества обучения через игры, чтобы учителя и школы могли понять потенциал интеграции образовательной игровой платформы обучения в свой класс.

Игры побуждают студентов и детей играть вместе. Во многих играх игроки должны работать вместе в командах для достижения целей или соревноваться друг с другом. Для этого студенты должны улучшить свои коммуникативные навыки: это поможет им установить лучшие отношения и повысить самооценку.

Многие учителя классической литературы приносят в класс игры-визуализации, чтобы объяснить путешествие Одиссея. По словам Пола Дарваси, «Игры в альтернативной реальности можно использовать как иммерсивную обучающую систему, сочетающую в себе богатое повествование, цифровые технологии и реальный игровой процесс. Студенты должны проявлять критическое мышление, стойкость и творческое решение проблем, чтобы добиться успеха в игре в альтернативной реальности».

Благодаря видеоиграм дети могут очень скоро заинтересоваться технологиями. Для них важно внедрить базовые технические навыки, такие как кодирование и программирование

Есть множество примеров успешных реализаций игр для образования в разных профессиональных сферах, приведу несколько примеров.

Начну с популярной игры Minecraft от компании Mojang.

В ней можно добывать ресурсы, а потом строить из них сооружения разной сложности. Игровой мир состоит из кубических блоков, потому строительство требует определенных навыков планирования и базовых знаний математики.

C помощью Minecraft в школах уже несколько лет обучают программированию, математике и командной работе. А в 2016 году компания Mojang совместно с Microsoft выпустила Minecraft Education Edition. 
Эта версия создавалась специально для школ. Она включает ряд улучшений, которые упрощают обучение программированию и оптимизируют совместную работу.

Несмотря на новый подзаголовок, Minecraft: Education Edition не слишком сильно отличается от своей стандартной версии. Это практически та же игра, но уже включающая в себя ряд инструментов, здорово упрощающих жизнь учителям. Так, преподаватели могут просматривать карту и видеть на ней учеников, давать им различные ресурсы и телепортировать их в определённые места. Также есть несколько специфичных для школы внутриигровых предметов - например, камера и доска.

Microsoft надеется, что в Minecraft: Education Edition ученики смогут весело проводить время, в то время как учителя будут использовать игру для обучения детей различным предметам. Учителя вынуждены будут создавать в игре миры, связанные с изучаемой темой, будь то некое окружение из книги или историческое сооружение. Так, в одном из примеров на сайте проекта была продемонстрирована огромная модель человеческого глаза.

Ho Minecraft не единственная игра в школах. Есть еще SimCityEdu, которая развивает навыки, необходимые для жизни в XXI веке. Недавнее обновление в SimCityEdu называется Pollution Challenge. В нем студенты должны строить город в условиях изменения климата. Таким образом игра учит решать реально существующую проблему.

Но это еще не всё. Существуют школы, где процесс обучения полностью основан на гейминге.

Почему же они по-прежнему так мало распространены?

Несмотря на то, что цифровые обучающие игры демонстрируют большой потенциал развития и интеграции в начальное обучение и обучение, их применение требует внимания, чтобы исключить все возможные слабые места из их надлежащего функционирования. Использование цифровых обучающих игр в классе начальной школы требует от учителя внимания к содержанию, структуре и параметрам дизайна. На этом этапе учитель играет важную роль в обеспечении качества обучения и участия учащихся. Помимо важности, роль учителя предполагает также творческий подход, поскольку ожидается, что он будет включать обучение на основе игр в свои методы обучения. Это происходит из-за того, что все учебные программы начальной 
школы не содержат подробных инструкций по правильному использованию цифровых образовательных игр. Таким образом, учителя призывают надлежащим образом интегрировать игры в свои методы обучения, сочетая игры с процессом обсуждения и дополнительными занятиями, без использования компьютера, поскольку игра сама по себе может сбить с толку пользователей. Также следует сочетать с другими образовательными средами, чтобы обеспечить обобщение знаний и их применение в других областях. При использовании цифровых образовательных игр в начальном образовании роль учителя разделяют и компьютер, и учащиеся, при этом каждый выполняет свою функцию

Чтобы играть, нужны дорогие устройства вроде планшетов или компьютеров, надежный интернет и возможность покупать сами игры. Конечно, со временем устройства дешевеют, а игры становятся доступнее (как Minecraft Education Edition), но проблема пока актуальна.

Наконец, существует мнение, что игры скорее отвлекают, чем обучают. Это справедливое опасение, но лишь в том случае, если учитель пускает всё на самотек. В такой ситуации нужно поработать над учебной программой или дополнительно проинструктировать учителя. При должной организации опасение можно отбросить.

Интерес исследователей к использованию игр и симуляторов в высшем образовании постоянно растет (Girard et al., 2013). Педагогический сдвиг от среды, ориентированной на лекции, к среде, ориентированной на студентов, и все более широкое использование игр в качестве инновационных технологий обучения требует преобразований в высшем образовании. В этом отношении ожидается, что игры и симуляторы будут играть важную роль в процессе обучения. В настоящем исследовании основное внимание уделяется положительному влиянию игр и симуляторов на результаты обучения студентов университетов.

Для изучения всех факторов и параметров использования и интеграции цифровых образовательных игр в начальное образование необходимо проведение дальнейших исследований. Также есть предложения по разработке и созданию соответствующих цифровых образовательных игр с использованием современных сценариев и совместимости с ожидаемыми результатами обучения. В конечном итоге это позволит активно участвовать всем пользователям-учащимся и создавать сообще- 
ства цифрового обучения, что сделает процесс обучения более приятным и увлекательным.

\section{ヘнтература}

1. Федянин Я. «Серьезные игры», симуляции и виртуальные миры: как соотносятся эти понятия? (Исследование Futurelab), http://premiumconsult.blogspot.com/2011/04/futurelab. html // Premium consulting. - 11.04.11.

2. Андреу Андрес, Массачусетс и Гарсиа Касас. Восприятие игр студентами инженерных специальностей как экспериментальное обучение. М., 2011.

3. Баклунд П., и Хендрикс. Развивающие игры - стоит ли затраченных усилий? Литературный обзор эффективности серьезных игр. М., 2013.

4. Бекебреде Г., Вармелинк, HJG, и Майер И.С. Анализ потребности в играх в образовании, чтобы приспособиться к сетевому поколению. 2011. 